\title{
CAN KNOWLEDGE REALLY BE NON-FACTIVE?
}

\author{
Michael J. SHAFFER
}

\begin{abstract}
This paper contains a critical examination of the prospects for analyses of knowledge that weaken the factivity condition so that knowledge implies only approximate truth.
\end{abstract}

KEYWORDS: knowledge, factivity, falsehoods, assertion, inconsistency, epistemic logic

\section{Introduction}

The decidedly timeworn and orthodox analysis of the nature of knowledge is that knowledge is justified true belief. So,

(JTB) $\mathrm{S}$ knows that $\mathrm{p}$, if and only if,

(i) $\mathrm{S}$ believes that $\mathrm{p}$,

(ii) S's belief that $\mathrm{p}$ is justified and

(iii) $\mathrm{p}$ is true.

Though this analysis is now discredited, (i), (ii) and (iii) were supposed to be individually necessary and jointly sufficient for knowledge. JTB was thus supposed to be a sort of decompositional and hence informative analysis of the nature of knowing. However, as we all now know, in 1963 Edmund Gettier (at least on the common interpretation) showed that the JTB account of knowledge is incorrect. ${ }^{1}$ What Gettier specifically did was to present two cases where conditions (i)-(iii) were met but where our intuitions are supposed to be that the agent in question does not have knowledge. ${ }^{2}$ In effect Gettier challenged the sufficiency of the JTB account on the basis of the following sort of case. Consider the case of Smith. ${ }^{3}$ We are to suppose that Smith has strong evidence for the claim that Jones owns a Ford. This evidence

${ }^{1}$ Edmund Gettier, “Is Justified True Belief Knowledge?” Analysis 23 (1963), 121-123.

${ }^{2}$ It is worth mentioning that Gettier's case for the rejection of the JTB account only follows as a deductive consequence given the assumptions of epistemic closure and the idea that one can be justified in holding a false belief.

${ }^{3}$ Gettier "Is Justified True," 122.

(C) LOGOS \& EPISTEME, XII, 2 (2021): 215-226 
includes that Jones has always owned a Ford and that Jones has just offered a ride to Smith while driving a Ford. Suppose also that Smith has a friend Brown and that Smith does not know where Brown currently is. So Smith formulates the following beliefs. Either Jones owns a Ford or Brown is in Boston. Either Jones owns a Ford or Brown is in Barcelona. Either Jones owns a Ford or Brown in Brest-Litovsk. All three are entailed by the claim that Jones owns a Ford. But, suppose that Jones does not in point of fact own a Ford, say he is presently driving a rental car. Moreover, by coincidence suppose that unknown to Smith Brown is actually in Barcelona. This means that Smith meets conditions (i)-(iii) of the JTB analysis, but intuitively we do not believe that Smith knows that either Jones owns a Ford or Brown is in Barcelona. What has happened is that Smith's belief has been caused in some inappropriate manner and the truth of his justified belief is, in some important sense of the term, a matter of luck. Of course, the intuition is supposed to be widely shared by philosophers and Gettier's cases have been widely taken to refute the JTB analysis of knowledge. Importantly, in light of this result, many practitioners of post-Gettier epistemology have then been concerned with the offering of an alternative analysis of knowledge, prominently including "fourth condition" analyses (JTB+ analyses) that are intentionally designed rule out Gettier cases as involving bona fide knowledge. ${ }^{4}$

There is, however, another line of thought that has arisen out of the challenge that Gettier's ruminations about the adequacy of the JTB analysis. Specifically and even more controversially, some thinkers have raised concerns about the necessity of condition (iii) of the JTB/JTB+ analyses despite wide-spread agreement that it should be part of a correct analysis of knowledge. ${ }^{5}$ That is to say, these thinkers have raised concerns about the orthodox factivity condition on knowing. ${ }^{6}$ Most

${ }^{4}$ See Peter Unger, "An Analysis of Factual Knowledge," Journal of Philosophy (1968): 157-170,
George Pappas and Marshall Swain (eds.), Essays on Knowledge and Justification (Ithaca: Cornell
University Press, 1978), Robert Shope, The Analysis of Knowing (Princeton: Princeton University
Press, 1983), and Ram Neta, "Defeating the Dogma of Defeasibility," in Williamson on Knowledge,
eds. Patrick Greenough and Duncan Pritchard (Oxford: Oxford University Press, 2009), 161-182
for a survey of the variety of post-Gettier accounts of knowledge.
${ }^{5}$ See, for example, Duncan Pritchard, Knowledge (London: Palgrave Macmillan, 2009), Robert
Audi, Epistemology: A Contemporary Introduction to the Theory of Knowledge (New York:
Routledge, 1998), Laurence BonJour, Epistemology: Classic Problems and Contemporary
Responses (New York: Rowman \& Littlefield, 2002), Roderick Chisholm, Theory of Knowledge
(Englewood Cliffs, NJ: Prentice Hall, 1989) and Jonathan Jenkins Ichikawa and Mathias Steup,
"The Analysis of Knowledge" The Stanford Encyclopedia of Philosophy(Summer 2018 Edition),
Edward N. Zalta (ed.), URL = <https://plato.stanford.edu/archives/sum2018/entries/knowledge-
analysis/>. 
prominently, Buckwalter and Turri have recently claimed that knowledge simply does not entail strict truth. ${ }^{7}$ Notice that dropping the factivity condition amounts to the contention that epistemic agents can, at least sometimes, know propositions that are false. This line of thought has some independent support in the form of observations concerning the prevalence of approximations in human cognition. In fact, a number of philosophers and psychologists have compellingly argued that rational thinking and acting involves the use of all sorts of approximations, idealizations and/or inexact truths far more often than epistemologists have previously acknowledged. ${ }^{8}$ That we are less than perfectly rational is, of course, not at all a new recognition and the work of the various defenders of the heuristics and biases tradition, the ecological rationality model and some more traditional views attests to this. ${ }^{9}$ What is most relevant here is that this line of thinking strongly suggests that we sometimes base both practical and theoretical reasoning on propositions that are not-exactly-true and that we can be efficient problem solvers and deliberators in even though we do not reason in maximally accurate ways on the basis of exact truths. In other words, we often trade degrees of accuracy with respect to truth for things like efficiency, ease of use and generality without seemingly compromising rationality or success. So, there is nothing at all unusual about employing approximate, partial or inexact truths in our epistemic practices. This sort of sentiment is reflected in claims about epistemic states and their acceptance like this one: "...epistemic acceptability turns not on whether it [a proposition] is true, but on whether it is true enough-that is, on whether it is close

Allan Hazlett, "The Myth of Factive Verbs," Philosophy and Phenomenological Research 80 (2010): 497-522,

7 Wesley Buckwalter and John Turri, "Knowledge and Truth: A Skeptical Challenge," Pacific Philosophical Quarterly (forthcoming).

8 See Catherine Elgin, Considered Judgment (Princeton: Princeton University Press, 1996), Catherine Elgin, “True Enough," Philosophical Issues 14 (2004): 113-131, Nancy Cartwright, How the Laws of Physics Lie (Oxford: Oxford University Press, 1983), Elijah Millgram, Hard Truths (London: Wiley-Blackwell, 2009), Paul Teller, "Twilight of the Perfect Model," Erkenntnis 55 (2001): 393-415, Paul Teller, "The Finewright Theory," in Nancy Cartwright's Philosophy of Science, edited by Stephan Hartmann, Carl Hoefer and Luc Bovens, 91-116. London: Routledge, 2008), Mark Wilson, Wandering Significance (Oxford: Oxford University Press, 2006) and William Wimsatt, Re-engineering Philosophy for Limited Beings: Piecewise Approximations to Reality (Cambridge: Harvard University Press, 2007).

9 See, for example, Christopher Cherniak, Minimal Rationality (MIT Press: Cambridge, 1986), Renée Elio (ed.), Common Sense, Reasoning and Rationality (Oxford: Oxfrod University Press, 2002), Massimo Piattei-Palmarini, Inevitable Illusions (New York: Wiley, 1994) and Gerd Gigerenzer, Adaptive Thinking (Oxford: Oxford University Press, 2000). 
enough to the truth." ${ }^{10}$ However, on this basis, one might be tempted to draw the rather extreme and pessimistic skeptical conclusion that we do not really know very much at all, especially if one maintains strict factivity of knowledge proper. ${ }^{11}$ Moreover, on this basis one might be tempted to re-orient epistemology on something other than knowledge. Alternatively, dropping the strict factivity condition might be one way to avoid this extreme skeptical conclusion, avoid giving up on the concept of knowledge and take seriously the observations about approximation. The rather radical alternative proposal under consideration here is then that these sorts of observations about approximation are best dealt with by revising the analysis of knowledge itself. The most obvious and reasonable proposal of this sort, as explicitly pursued by Buckwalter and Turri, involves replacing (iii) with a weakened necessary condition related to factivity but framed in terms of approximate truth. ${ }^{12}$ In other words, the view in question here holds that we should adopt the view that knowing implies approximate truth rather than strict truth. Let us call this view the quasi-factivist account of knowledge.

\section{Quasi-factive Knowledge and Approximate Truths}

Quasi-factivism about knowledge is then the suggesting of something like the following alternative to the JTB/JTB+ analyses of knowledge:

(JATB+) S knows that $\mathrm{p}$, if and only if,

${ }^{10}$ Catherine Elgin, True Enough (Cambridge: MIT Press, 2017), 16. Although Elgin does not endorse the view to be discussed here (i.e. that knowledge entails only approximate truth) she does suggests re-focusing epistemology on the concept of acceptance rather than on belief. See Elgin, True Enough, 3. The distinction between acceptance and belief is defended in L. Jonathan Cohen, An Essay on Belief and Acceptance (Oxford: Clarendon Press, 1992).

${ }^{11}$ Peter Unger infamously defended this position in his book Ignorance (Oxford: Oxford University Press, 1975). The quasi-factivist view of knowledge is then pretty clearly intended to avoid having to draw this conclusion on the basis of the recognition of the prevalence of approximations in human cognition. Notice also that this line of argumentation very closely parallels the idealization argument against scientific realism as discussed, for example, in Nancy Cartwright, How the Laws of Physics Lie(Oxford: Oxford University Press, 1983), Lawrence Sklar, Theory and Truth (Oxford: Oxford University Press, 2000), and Michael Shaffer, Counterfactuals and Scientific Realism (New York: Palgrave MacMillan, 2012). More specifically, see Buckwalter and Turri, "Knowledge and Truth," for an attempt to avoid this skeptical conclusion.

12 See Buckwlater and Turri, "Knowledge and Truth." They are explicit about adopting this view and claim that "We propose a fourth response: knowledge does not require truth (i.e. reject Line 1). Instead, false but approximately true propositions can be known. Call this the approximation account of knowledge. On this view, representations need not be true in order to count as knowledge (5)." 
(i) $\mathrm{S}$ believes/accepts that $\mathrm{p}$,

(ii) S's belief that $\mathrm{p}$ is justified,

(iii') $\mathrm{p}$ is approximately true and

(iv) S's justified belief that $\mathrm{p}$ meets the required "additional anti-luck condition(s)".

So, here (iv) (in an admittedly vague manner) is meant to indicate the idea that knowledge requires some sort of anti-luck condition necessary to secure reliability and stave off Gettier cases. ${ }^{13}$ More importantly for the purposes at hand, (iii') is the condition that knowledge is "quasi-factive." 14 Accordingly, given JATB+ one can know at least some false propositions, specifically one can know approximate truths when all of the other conditions for knowing are met. This might seem to be a prima facie compelling view given how common approximation and hedging are in human cognition, but is it really defensible to suppose that one can really ever know a false but approximately true proposition? The answer defended here is an emphatic "no." This is the case because here are at least three serious problems with the quasifactivist view of knowledge.

\section{The Inconsistency and Explosion Objection}

The first problem for the quasi-factivist about knowledge has to do with the following deeply troubling consideration related to inconsistency, closure and the logical principle known as ex contradictione (sequitur) quodlibet (ECQ). Suppose that the quasi-factivist about knowledge is right and one can know propositions that are approximately true. By definition all approximate truths are false and so the quasi-factivist about knowledge is thereby committed to the idea that some falsehoods can be known. ${ }^{15}$ Consider then a claim $\mathrm{p}$ that is approximately true ATp

${ }^{13}$ See Peter Unger, “An Analysis of Factual Knowledge," Journal of Philosophy (1968): 157-170 and Alvin Goldman, "Williamson on Knowledge and Evidence," in Williamson on Knowledge, ed. Greenough and Pritchard, 73-91. There, concerning the JTB account, Goldman tells us, "It is obviously incomplete, and we have some fairly good ideas about how to repair it, or at least to improve upon it. That is not to say that there is unanimity among epistemologists. Nevertheless, some sort of additional conditions in an "anti-luck" vein are widely agreed to be necessary for a satisfactory account of knowing (75)."

${ }^{14}$ See Michael Shaffer, "Approximate Truth, Quasi-factivity and Evidence," Acta Analytica 30 (2015): 249-266.

15 See Risto Hilpinen, "Approximate Truth and Truthlikeness," in Formal Methods in the Methodology of the Empirical Sciences, ed. Marian Przelecki, et al. (Dordrecht: Reidel, 1976), 1942, Theo Kuipers, What is Closer-to-the-truth? (Amsterdam: Rodopi, 1978), Graham Oddie, Likeness to Truth (Dordrecht: Reidel, 1986), Graham Oddie, "Truthlikeness," The Stanford 
and which is known, Ksp, by some epistemic agent S. For example, suppose that (in the quasi-factivist sense), after properly conducting a rigorous measurement using measurement process $M$, Joe knows that the value of some measured variable $\mathrm{x}$ is $5.6 u$ but where the real value of $x$ is $5.600000000001 u$. ${ }^{16}$ That the value of $x$ is $5.6 u$ is then only approximately true. On this basis, the quasi-factivist view allows for the following state to obtain Ksp \& ATp. But, suppose that $\mathrm{S}$ knows that $\mathrm{p}$ is approximately true KsATp and is aware of the fact that all approximate truths are false. Since ATp then implies $\neg$ p and (as we shall see shortly) knowledge is closed under implication (even for quasi-factivists about knowledge), in such a situation $\mathrm{Ksp}$ and $\mathrm{Ks} \neg \mathrm{p}$. Returning to our example let us suppose then that Joe knows that it is only approximately true that the value of $\mathrm{x}$ is $5.6 \mathrm{u}$ and that, on this basis and his understanding of the nature of approximate truth, Joe knows that it is false that the value of $\mathrm{x}$ is $5.6 \mathrm{u}$. So, Joe knows that the value of $\mathrm{x}$ is $5.6 \mathrm{u}$ and he knows that it is not the case that the value of $\mathrm{x}$ is $5.6 \mathrm{u}$. It should be obvious that this is deeply troubling. Such reflective knowledge of approximate truths entails knowledge of contradictions. However, this is not even yet as brutally damaging from an epistemic perspective as it in point of fact turns out to be, because we have not yet seen how this gives rise to the problem of epistemic explosion. Let us proceed by looking a bit more carefully at the logic of knowledge and the extent of this problem will become clear.

The standard axiomatization of the logic of knowledge is KDT. ${ }^{17}$ The relevant axioms that constitute this system and its stronger and weaker relatives are as follows:
$(\mathbf{K}) \mathrm{Ks}(\mathrm{p} \rightarrow \mathrm{q}) \rightarrow(\mathrm{Ksp} \rightarrow \mathrm{Ksq})$
(D) $\mathrm{Ksp} \rightarrow \neg \mathrm{Ks} \neg \mathrm{p}$
(T) Ksp $\rightarrow \mathrm{p}$
(4) $\mathrm{Ksp} \rightarrow \mathrm{KsKsp}$
(5) $\neg \mathrm{Ksp} \rightarrow \mathrm{Ks} \neg \mathrm{Ksp}$

\footnotetext{
Encyclopedia of Philosophy (Fall 2008 Edition), Edward N. Zalta (ed.), URL= <http://plato.stanford.edu/archives/fall2008/entries/truthlikeness/>.

${ }^{16}$ Here "u" is some arbitrary unit of measurement. See Michael Shaffer, "Rescuing the Assertability of Measurement Reports," Acta Analytica 34 (2019): 39-51 for some problems about these sorts of cases as they relate to approximation, assertion and knowledge

17 See Vincent Hendricks and John Symons, "Epistemic Logic," The Stanford Encyclopedia of Philosophy(Fall 2015 Edition), Edward N. Zalta (ed.), URL = <https://plato.stanford.edu/ archives/fall2015/entries/logic-epistemic/>.
} 
(.2) $\neg \mathrm{Ks} \neg \mathrm{Ksp} \rightarrow \mathrm{Ks} \neg \mathrm{Ks} \neg \mathrm{p}$

(.3) $\mathrm{Ks}(\mathrm{Ksp} \rightarrow \mathrm{Ksq}) \vee \mathrm{Ks}(\mathrm{Ksq} \rightarrow \mathrm{Ksp})$

$(.4) \mathrm{p} \rightarrow(\neg \mathrm{Ks} \neg \mathrm{Ksp} \rightarrow \mathrm{Ksp})$

What is of great importance here is that $\mathrm{K}$ in particular generalizes to the principle of closure for knowledge and even the logic of quasi-factive knowledge must obey $\mathbf{K}$, though it explicitly does not obey $\mathbf{T}$. The knowledge closure principle based on $\mathbf{K}$ is often then rendered simply as follows:

(SCK) If Ksp and $\mathrm{Ks}(\mathrm{p} \rightarrow \mathrm{q})$, then Ksq.

Now this version of the principle, the subjective closure of knowledge under material implication, says that if $\mathrm{S}$ knows $\mathrm{p}$ and also knows that $\mathrm{p}$ materially implies $\mathrm{q}$, then $\mathrm{S}$ knows $\mathrm{q}$. There is however a stronger version of the principle, objective closure of knowledge under material implication as follows:

(OCK) If Ksp and ( $\rightarrow$ q), then Ksq.

This version of the closure principle states that if $\mathrm{S}$ knows a proposition, then $\mathrm{S}$ knows all of the material implications of that proposition. In the argument that follows we need only assume SCK (grounded on the basis of axiom K) and stipulate that $S$ is a reflective agent who knows the relevant implications built into the constructed (but totally generic) example introduced above. All of this guarantees that $\mathrm{Ksp}$ and $\mathrm{Ks} \neg \mathrm{p}$ implies $\mathrm{Ks}(\mathrm{p} \& \neg \mathrm{p})$. But, if this is true, then S knows everything due to the epistemic explosion problem that arises in virtue of ECQ and SCK. But, what exactly is ECQ? ECQ is a rather surprising but valid argument form in classical deductive logic. So it is a theorem of classical logic. Its proof is quite simple:

$$
\begin{aligned}
& \text { P1: }(\mathrm{p} \& \neg \mathrm{p}) \quad \text { assumption } \\
& \text { P2: } \mathrm{p} \quad \text { conjunction elimination }[\mathrm{P} 1] \\
& \text { P3: } \neg \mathrm{p} \quad \text { conjunction elimination }[\mathrm{P} 1] \\
& \text { P4: } \mathrm{p} \vee \mathrm{q} \quad \text { disjunction introduction [P2] } \\
& \text { P5: } \mathrm{q} \quad \text { disjunctive syllogism [P3, P4] } \\
& \therefore(\mathrm{p} \& \neg \mathrm{p}) \rightarrow \mathrm{q} \quad \text { conditional proof }[\mathrm{P} 1-\mathrm{P} 5]
\end{aligned}
$$

Of course, this generalizes for any q whatsoever and so every contradiction validly implies every proposition in the context of classical logic. So if (reflectively) Ksp \& KsATp., ECQ is valid and knowledge in governed by SCK, then S would know everything. Based on the quasi-factivist account of knowledge, knowing an approximately true proposition in the reflective sense noted here logically entails knowing every proposition. But, this is absurd. Knowing a single approximate truth 
should not entail omniscience. So, JATB+ cannot possibly be the correct analysis of knowledge.

\section{The Safety Objection}

The second, equally devastating, objection to JATB+ arises out of considerations having to do with the safety condition on knowledge. The safety condition for knowledge is a condition for knowing that has been most systematically defended by Williamson, Sosa and Pritchard. ${ }^{18}$ This condition, among other things, is supposed to ground the difference between knowledge and lucky true belief (especially of the sort involved in Gettier cases) by introducing an element of reliability into the definition of knowledge that is lacking in the case of luckily true beliefs. In other words, it is supposed to do the work required of condition (iv) of the JTB+ analysis. ${ }^{19}$ The safety condition can be understood simply as follows:

If $\mathrm{S}$ knows that $\mathrm{p}$, then $\mathrm{S}$ could not easily have falsely believed that $\mathrm{p}$.

This relatively non-technical gloss on safety and it can be made more precise in modal terms as follows:

$$
\text { (Safety) }\left(\mathrm{w}_{\mathrm{i}} \vDash \mathrm{Ksp}\right) \rightarrow \neg\left[<\mathrm{w}_{\mathrm{i}}>\vDash\left(\mathrm{B}_{\mathrm{s}^{\prime}} \mathrm{p} \& \neg \mathrm{p}\right)\right] \text {. }
$$

Here 'wi' is world i, 'Ksp' represents that $\mathrm{S}$ knows that $\mathrm{p}$, '< $\mathrm{w}_{\mathrm{i}}>$ ' is the set of worlds sufficiently close to $\mathrm{w}_{\mathrm{i}}$, and ' $\mathrm{B}_{\mathrm{s}} \mathrm{p}$ ' represents that $\mathrm{S}$ believes that $\mathrm{p}$. So understood, the safety condition is the claim that if $S$ knows that $p$, then there are no worlds sufficiently similar to $\mathrm{w}_{\mathrm{i}}$ (including $\mathrm{w}_{\mathrm{i}}$ ) where $\mathrm{S}^{\prime}$ (S's counterpart in those worlds) believes that $\mathrm{p}$ and $\mathrm{p}$ is false. This regimentation of the safety condition captures the core idea of that condition well and the contrapositive of safety is also interesting to note:

(Contrapositive Safety) $\left[<\mathrm{w}_{\mathrm{i}}>\vDash\left(\mathrm{B}_{\mathrm{s}^{\prime}} \mathrm{p} \& \neg \mathrm{p}\right)\right] \rightarrow \neg\left(\mathrm{W}_{\mathrm{i}} \vDash \mathrm{K}_{\mathrm{s}} \mathrm{p}\right)$.

This version of safety essentially is the assertion that if S could easily have falsely believed that $\mathrm{p}$, then $\mathrm{S}$ does not know that $\mathrm{p}$. More technically, it is the claim that if

18 Timothy Williamson, Knowledge and its Limits (Oxford: Oxford University Press, 2000), Ernest Sosa, "How to Defeat Opposition to Moore," Philosophical Perspectives 13 (1999): 141-54, Duncan Pritchard, "Anti-Luck Epistemology," Synthese 158 (2007): 277-98, Duncan Pritchard, "Knowledge, Luck, and Lotteries," in New Waves in Epistemology, eds. Vincent Hendricks and Duncan Pritchard (London: Palgrave Macmillan, 2008): 28-51, Duncan Pritchard, "Safety-Based Epistemology: Whither Now?" Journal of Philosophical Research 34 (2009): 33-45, and Duncan Pritchard, Knowledge (London: Palgrave Macmillan, 2009).

${ }^{19}$ See Michael Shaffer, “An Argument for the Safety Condition," Logos \& Episteme 8 (2017): 517520 for an argument that the safety condition is, in fact, implied by the JTB analysis. 
in worlds sufficiently similar to $\mathrm{w}_{\mathrm{i}} \mathrm{S}$ believes that $\mathrm{p}$ and $\mathrm{p}$ is false, then $\mathrm{S}$ does not know that $\mathrm{p}$ at $\mathrm{wi}$. The easiest way then to see why safety should be regarded as a necessary condition for knowing is to understand what the denial of safety involves. It involves this:

(Unsafe Knowledge) $\left(\mathrm{w}_{\mathrm{i}} \vDash \mathrm{Ksp}\right) \&\left[<\mathrm{wi}_{\mathrm{i}}>\vDash(\mathrm{Bsp} \& \neg \mathrm{p})\right]$.

Knowing $p$ at a given world is compatible with falsely believing $p$ in worlds close to that given world. But, it must be the case that $\mathrm{w}_{\mathrm{i}} \in\left\langle\mathrm{w}_{\mathrm{i}}\right\rangle$. This because any account of closeness (i.e. any account of world similarity) must be reflexive and every world is maximally similar to itself. Thus, denying safety entails that one can know a claim at a world where that claim is false. But, this is absurd for all the familiar reasons. But notice now that, in virtue of JATB+, the quasi-factivist is automatically committed to the idea that there can be unsafe knowledge! In fact, according to the quasi-factivist one can have knowledge of $\mathrm{p}$ at a world where $\mathrm{p}$ is just false: $\mathrm{w}_{\mathrm{i}} \vDash \mathrm{Ksp}$ $\& \neg$ p. The problem then is that in adopting (iii') the quasi-factivist thereby automatically rejects safety and thus deprives themselves of this sort of reliability condition that allows for the satisfaction of (iv). This then deprives them of an important resource that allows for dealing with Gettier problems and other problems related to epistemic luck. Perhaps there is some other sort of account of a condition that could do the work of (iv) that is compatible with the quasi-factivist view, but it is at best unclear what this might principle be or even what such a condition might look like.

\section{The Moorean Objection}

The third objection raised here against the quasi-factivist view of knowledge concerns explaining the infelicity of claims of the following sort: "I know that p, but $p$ is false." Let us call these sorts of claims Moorean knowledge claims and they have the following form: Ksp \& $\neg$ p. Given JTB/JTB+ analyses of knowledge where the logic of knowledge is at least as strong as KDT the infelicity of Moorean knowledge claims is easily explained. According to T and its incorporation in JTB/JTB+ in the form of condition (iii), $\mathrm{Ksp} \rightarrow \mathrm{p}$ and so the utterance of a claim to the effect that "I know that $\mathrm{p}$, but $\mathrm{p}$ is false" is just the utterance of a (very) thinly veiled contradiction. For example, the assertion of the claim that "I know that electrons are negatively charged, but it is false that electrons are negatively charged" does not seem to be a legitimate assertion and according to the factivist about knowledge it is illegitimate because it is contradictory.

For these sorts of reasons (and some other related ones) many variously motivated thinkers have defended the view that the proper norm for assertion is 
knowledge. ${ }^{20}$ Timothy Williamson in particular has strongly defended the knowledge norm for assertion on this basis. ${ }^{21}$ In its most elemental form, this principle is the following claim:

(KNA) one should assert a proposition only if it is known.

Now, the knowledge norm of assertion has been subjected to considerable criticism, but it has also been vigorously defended by some influential contemporary philosophers. ${ }^{22}$ Williamson in particular defends the knowledge norm for assertion by appeal to its supposed explanatory power, especially with respect to the infelicity of Moorean belief claims of the form "p, but I do not believe that p." Specifically, he argues that the knowledge norm of assertion is the best explanation of the unassertability of such claims and this is, of course, closely related to the problem raised here about Moorean knowledge claims and the quasi-factivist view of knowledge. In mounting this defense Williamson claims that Moorean sentences are (1) unassertable and (2) that the best explanation of this fact is that knowledge is the proper norm of assertion.

So why is the alleged unassertability of Moorean claims supposed to support the knowledge norm of assertion, especially in the case of factive accounts of knowledge? This is supposed to be the case because if asserting that $\mathrm{p}$ is governed by the norm of knowledge and knowledge is factive, then it follows that one should assert $\mathrm{p}$ only if it is true. Thus, on this version of the knowledge norm view, to assert a Moorean sentence is to violate the knowledge norm of assertion and the infelicity of such assertions is just a consequence of any version of KNA involving factivity. Essentially, one ought not to assert that $\mathrm{p}$ when $\mathrm{p}$ is not believed or when it is false because then it cannot be known according to the JTB/JTB+ interpretations of the knowledge norm. There are of course, several extant weaker proposals than the knowledge norm, but the same point will hold for any account of the norm of assertion that is factive. ${ }^{23}$ The problem then for the quasi-factivist about knowledge

\footnotetext{
${ }^{20}$ See Jessica Brown, "Fallibilism, and the Knowledge Norm for Assertion and Practical Reasoning," in Assertion: New Philosophical Essays, eds. Jessica Brown and Herman Cappelen (Oxford: Oxford University Press, 2011), 153-174.

${ }^{21}$ Timothy Williamson, Knowledge and its Limits (Oxford: Oxford University Press, 2000).

${ }^{22}$ See, for example, Jonathan Hawthorne, Knowledge and Lotteries (Oxford: Oxford University Press, 2004), Jonathan Hawthorne and Jason Stanley, "Knowledge and Action," The Journal of Philosophy 105 (2008): 571-590, Timothy Williamson, Knowledge and its Limits (Oxford: Oxford University Press, 2000), Timothy Williamson, "Contextualism, Subject-Sensitive Invariantism and Knowledge of Knowledge,” The Philosophical Quarterly 55 (2005): 213-235.

${ }^{23}$ See Michael Shaffer, "Not-Exact-Truths, Pragmatic Encroachment and the Epistemic Norm of Practical Reasoning," Logos \& Episteme 3 (2012): 239-259, Michael Shaffer "Moorean Sentences
} 
who endorses KNA is how to explain the infelicity of Moorean knowledge claims. Presumably, the only option open to the non-factivists about knowledge with respect to this issue is to deny that (at least some) Moorean knowledge claims are, in fact, infelicitous. According to JATB+ knowledge only implies approximate truth and in cases where we have the assertion that $\mathrm{S}$ knows $\mathrm{p}$ and $\mathrm{p}$ is false due to its approximate truth, there would be no need for an explanation of the infelicity involved. In other words, if JATB+ is correct, there should be no appearance of such infelicity and so there is no need to explain such infelicities. But these claims do appear to be infelicitous and so it is simply a mystery why this is so if JATB+ is correct and one endorses KNA.

However, there is another related problem here about assertability that arises for quasi-factivists about knowledge who endorse KNA. Specifically, if JATB+ is correct and one endorses KNA, then it seems perfectly felicitous to assert contradictory pairs of claims. Given JATB+ let us suppose that Joe properly conducts a rigorous measurement using measurement process $\mathrm{M}$ and so, on the basis of (iii') in particular, knows that the value of some measured variable $\mathrm{x}$ is $5.61 \mathrm{u}$ but where the real value of $x$ is $5.6 u$. Further suppose, that to be careful Joe rigorously measures the value of $x$ again using $M$ and obtains the result that the value of $x$ is $5.59 u$ and so also knows that the value of $x$ is $5.59 u$. That the value of $x$ is 5.61 and that the value of $\mathrm{x}$ is $5.59 \mathrm{u}$ are both only approximately true relative to the true value of $5.6 \mathrm{u}$, but they are approximately true to the very same degree. ${ }^{24}$ But, that the value of $\mathrm{x}$ is $5.59 \mathrm{u}$ implies that the value of $\mathrm{x}$ is not $5.61 \mathrm{u}$ and vice versa. Thus, unless the quasifactivist has some appropriate response, it appears to be the case that given the JATB+ account of knowledge Joe can know and assert both that "I know that the value of $\mathrm{x}$ is $5.59 \mathrm{u}$, but it is false that the value of $\mathrm{x}$ is $5.59 \mathrm{u}$ " and "I know that the value of $\mathrm{x}$ is $5.61 \mathrm{u}$, but it is false that the value of $\mathrm{x}$ is $5.61 \mathrm{u}$ ". The appearance of infelicity in such pairs of cases of assertions of Moorean sentences is, however, undeniable and so even if the quasi-factivist somehow denies the infelicity of individual Moorean knowledge claims this is not apparently an option with respect to pairs of cases like

and the Norm of Assertion," Logos \& Episteme 3 (2012): 653-658, Ram Neta, "Treating Something as a Reason for Knowledge," Nous 43 (2009): 684-699, and Clayton Littlejohn, "Must We Act Only on What We Know," The Journal of Philosophy 106 (2009): 463-473 for discussions of this issue. ${ }^{24}$ Notice that this observation further exacerbates the inconsistency problems that the quasifactivist faces that were raised earlier. Notice also that such pairs (or larger sets) of such claims do not even need to be of the same degree of approximate truth. According to JATB+ knowledge implies approximate truth simpliciter and so an appropriately poised epistemic agent would potentially know every approximation with respect to a strictly true claim all of which are mutually exclusive. 
Michael J. Shaffer

these. So, this constitutes another serious problem for the quasi-factivist view of knowledge.

\section{Quasi-factivity, Knowledge-like States and Knowledge}

So, the conclusion defended here is that the quasi-factivist view of knowledge is deeply problematic and considerations related to the prevalence of approximations in human cognition should not be used to motivate and justify the rejection of factivity. This is simply because the rejection of factivity entails a whole host of what appear to be catastrophic problems for the analysis of knowledge and for distinguishing knowledge from less valedictory sorts of belief. But, this leaves us with the worrisome possibility that the prevalence of approximations in human thinking implies an extreme form of skepticism. But, there is a middle ground here and the far less problematic position is that the prevalence of approximations in human cognition indicates only that there may well be all sorts of knowledge-like states, including quasi-factive and justified doxastic states, with all sorts of useful features of both the theoretical and practical sort. First and for the reasons articulated here, such quasi-factive states involving approximations should not be confused with knowledge. Second, we need to see how such states relate to the sorts of skeptical worries that are alleged to motivate quasi-factivism about knowledge. But, this second question requires us to have a theory of knowledge-like states that can be brought to bear given these skeptical worries. So, there appears to be a pressing need to explore the nature(s) of quasi-factive states that involve approximations and are knowledge-like. ${ }^{25}$

25 This project is worked out in Michael Shaffer, Quasi-factive Belief and Knowledge-like States (Lanham: Lexington, forthcoming). 